\title{
Development of Biliary and Enteral Stents by the Korean Gastrointestinal Endoscopists
}

\author{
Chan Sup Shim 1 , Jin Hong Kim² and Gene Hyun Bok ${ }^{3}$ \\ ${ }^{1}$ Digestive Disease Center, Konkuk University Medical Center, Konkuk University School of Medicine, Seoul, ${ }^{2}$ Department of \\ Gastroenterology, Ajou University Hospital, Ajou University School of Medicine, Suwon, ${ }^{3}$ Department of Internal Medicine, Min Hospital, \\ Seoul, Korea
}

Stenting in the gastrointestinal tract is a common procedure used for palliation of obstruction in the enteral and biliary tract. Today, stenting of malignant and benign strictures is performed at almost every major tertiary hospital in Korea. Moreover, Korea has become a major global supplier of cutting edge technology in the field of self-expanding metal stents. However, the history of stenting in Korea is relatively short and was far behind that of other nations such as Japan and Germany. The authors are humbled and gratified to have been able to observe the development and application of these stents in Korea, first hand. In this article, the authors review the overall history of stenting with a specific focus on the development of stenting in Korea. The development of esophageal, gastroduodenal, biliary, and colonic stents in Korea are reviewed in this article from a chronological and historical point of view, and a personal account of some of the significant moments of stent development in Korea are described. Clin Endosc 2016;49:113-123

Key Words: Biliary stent; Enteral stent; Self expandable metallic stents; Korea

\section{INTRODUCTION}

Seeing a smile on the face of a long suffering patient is often taken for granted, but it is moments like this that refresh a physician on a daily basis, and is the driving force that pushes one constantly forward. In 1983, a junior endoscopist named Chan-Sup Shim, who worked at the Digestive Disease Center in Soonchunhyang University Hospital in Seoul, Korea, had gone to Japan to study under Dr. Masatsugu Nakajima, who is known as the pioneer for initiating the endoscopic biliary drainage technique by inserting a hand-made, large bore (10 Fr), biliary, plastic stent via a large channel duodenoscope (4.2 $\mathrm{mm}$ in diameter, Olympus TJF10; Olympus, Tokyo, Japan). After learning the procedure, he returned to Korea with

Received: January 29, 2016 Accepted: February 16, 2016

Correspondence: Chan Sup Shim

Digestive Disease Center, Konkuk University Medical Center, Konkuk University School of Medicine, 120-1 Neungdong-ro, Gwangjin-gu, Seoul 05030, Korea Tel: +82-2-2030-7491, Fax: +82-2-2030-6182, E-mail: chansshim@kuh.ac.kr

(c) This is an Open Access article distributed under the terms of the Creative Commons Attribution Non-Commercial License (http://creativecommons.org/ licenses/by-nc/3.0) which permits unrestricted non-commercial use, distribution, and reproduction in any medium, provided the original work is properly cited. hands on experience, and performed his first solo procedure of biliary stenting in a patient suffering from obstructive jaundice resulting from cholangiocarcinoma, in 1985. It was the first case of large bore biliary stenting that was introduced to the Korean Society of Gastrointestinal Endoscopy. ${ }^{1}$ The results were dramatic and he was astonished by how rapidly the patients' symptoms were relieved. Medical technology has advanced greatly over the past 30 years in Korea. In contrast to the standardized stents of today, biliary stents of that time were designed and cut individually for each patient from a long polyurethane roll tube. The plastic roll tubes were placed over a steaming pot of water and both ends of the tube were stretched until gradually tapered, slender ends were formed. The tapered tubes would later be cut to just the right length for each patient and appropriate side holes and side flaps were created with a surgical blade (Fig. 1). Today, stents have undergone dramatic changes and are being routinely used in all fields of gastroenterology, such as esophageal, gastroduodenal, biliary, and colonic stenosis. It is well known that the Korean market is the leading developer of world-class gastrointestinal (GI) stents, notably the self-expandable metal stent (SEMS). The literature supporting the placement of stents in both be- 
nign and malignant conditions has increased exponentially, as also the variety of newly developed stents. The development of esophageal, gastroduodenal, biliary, and colonic stents in Korea will be reviewed in this article from a chronological and historical point of view.

\section{ESOPHAGEAL STENTING}

Today, esophageal stenting is a common practice for palliation of dysphagia caused by malignant disorders and for palliation of tracheoesophageal fistulae caused by either esophageal cancer or cancer of the lung. Esophageal stenting was first reported by Celestin ${ }^{2}$ in 1959. The Celestin tube is a rigid latex prosthesis that was used for permanent esophageal intubation in inoperable cancer of the esophagus and cardia. The Celestin tube was originally placed surgically via an anterior gastrostomy, but later on was placed perorally under endoscopic guidance. However, the Celestin tube was fraught with complications and underwent several modifications, such as being made with softer rubber material, a slimmer design, or the addition of a distal flange. Additionally, the diameter of the Celestin tube was fixed. Therefore, the stricture had to be dilated prior to placement in many cases. ${ }^{3}$ In 1977, Tytgat and den Hartog Jager ${ }^{4}$ described a method using a small caliber endoscope for non-surgical peroral placement of a plastic esophageal prosthesis in patients with obstructing cardio-esophageal malignancy, or with pulmonary-esophageal fistulas. Although the reported success rate for initial deployment of these rigid stents was approximately $95 \%$, the acute complication rates were extremely high. Complications like bleeding, perforation, tracheal compression, stent occlusion, migration, and fever were reported in as many as one-third of the cases. Most cases of fever, possibly occurred due to localized perforations, which were managed conservatively with

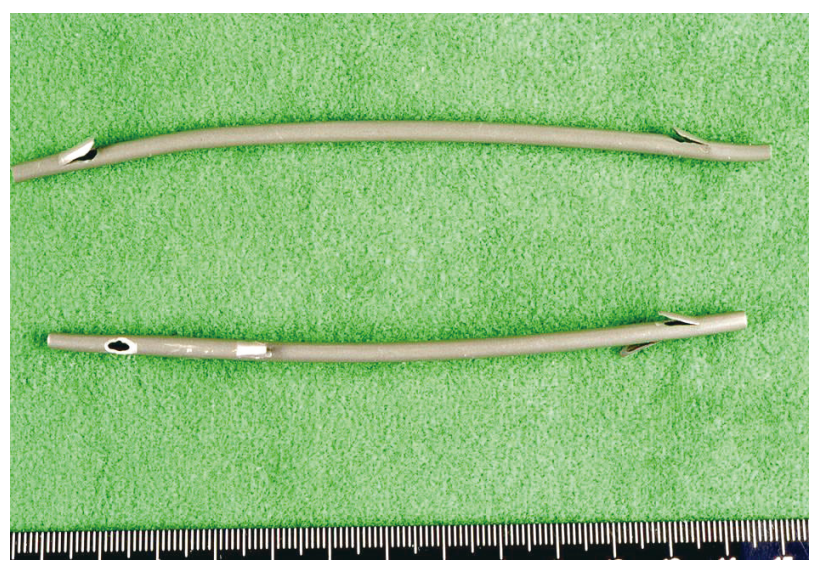

Fig. 1. Hand-made plastic biliary stent with side holes and side flaps $(10 \mathrm{~mm}$ in diameter). parenteral antibiotics and limited oral intake. Late complications included bleeding, perforation, migration, tumor overgrowth, and aspiration. There were also several reports of the latex of the Celestin tube disintegrating, which in turn caused complications such as bleeding, perforation, and obstruction. ${ }^{5}$ The first esophageal stenting in Korea was performed with a Celestin-Pulsion esophageal prosthesis by Shim et al. ${ }^{6}$ in 1986 (Fig. 2). He had just returned from the Amsterdam medical center (AMC) and was able to procure some of these newly developed stents.

Due to the high rate of complications, rigid stents were later inevitably replaced by SEMSs. Over the last 15 years, SEMSs have emerged as the treatment of choice for the palliation of malignant dysphagia. Indications for using SEMSs have expanded, while complications have reduced. Stent designs have undergone significant changes. SEMSs were initially introduced for use in the blood vessels and the biliary tree. However, once they were developed for use in the esophagus, they quickly and largely replaced neolumen-creating technologies. One of the first esophageal SEMSs to be developed was the EsophaCoil stent (InStent, Eden Prairie, MN, USA), a coilspring stent having a single-wire coiled configuration with two flanged ends, made from biocompatible nickel-titanium. However, there were several problems with this stent. Given its uncovered spring coil shape, repositioning was virtually impossible, once it was deployed. Tumor ingrowth was also an issue and this stent was soon withdrawn from the market. ${ }^{7}$ However, the EsophaCoil stent marked an important change for future stenting procedures. Improved designs soon followed, the most noticeable being the wire mesh stent. SEMSs in general produce a radial force against a narrow lumen after deployment. This radial force is driven by the inherent shape memory properties of the compressed alloy that constitutes the stent itself. Today most esophageal SEMSs use nitinol due to its durability, shape memory ability, and relative conformability, compared to other metallic materials such as stainless steel. Currently, numerous, commercially available esophageal stents can be partially or completely covered. Covered stents were mainly used to prevent tumor ingrowth or for palliation of tracheoesophageal fistulas. The first human report of application of covered esophageal SEMS was by Professor HoYoung Song in $1991^{8}$ (Table 1). He used a modified Gianturco Z-stent (Wilson-Cook, Winston-Salem, NC, USA) with a silicone membrane for palliation of malignant esophagogastric strictures. ${ }^{8}$ Modern esophageal stents are also diverse in shape and may come with distal or proximal flanges to prevent migration. The Choo stent, which is another covered esophageal SEMS (M.I. Tech, Seoul, Korea), was developed in 1995. This stent was covered with polyurethane, with 3-mm gaps between each metallic stent body part of stainless steel wire in a 

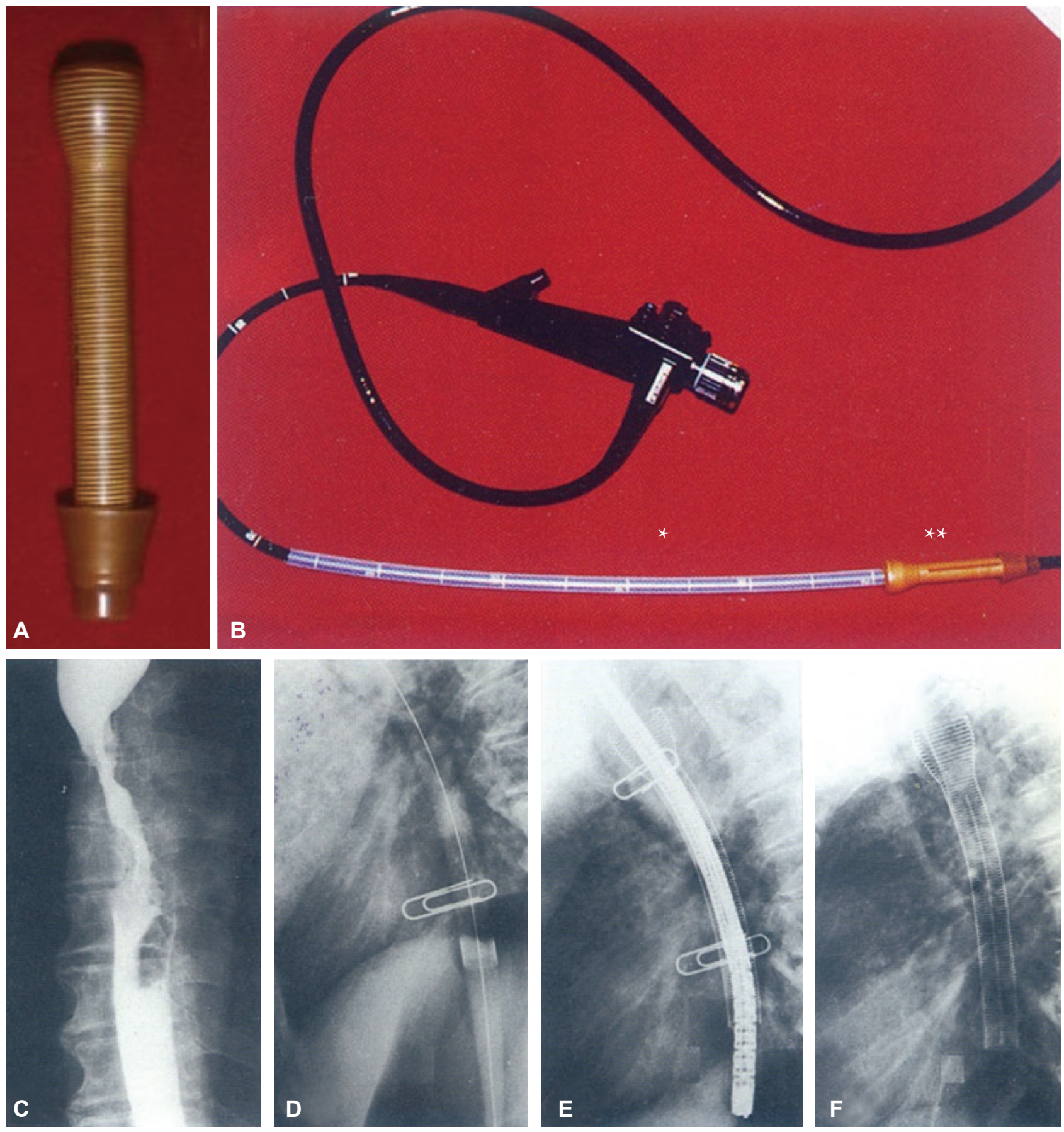

Fig. 2. Endoscopic esophageal stenting in esophageal cancer with a celestin stent. (A) Celestin stent. (B) Pusher tube $(*)$, stent $(* *)$. (C) Esophagogram of mid esophageal cancer. (D) Bougie dilation state. (E) Stent over the endoscope and pusher tube as an introducer clips for marking the length of tumor. (F) Stent just after deployment.

cylindrical zigzag fashion of 12 or 15 bends, so as to maximize its longitudinal flexibility. ${ }^{9}$ Other features such as proximal retrieval lassos to enable a deployed stent to be removed and replaced via endoscopic grasping forceps have been introduced, and in the case of stents placed at the esophagogastric junction causing lower esophageal sphincter disruption, anti-reflux stents with a specialized valve have been developed.
The Do stent, which is also a covered esophageal SEMS, but the first with an antireflux valve (M.I. Tech) made of three polyurethane leaflets attached to the distal part of the stent to prevent reflux, was developed in $1996 .^{10}$ A new anti-migration stent known as the double-layered esophageal stent (Taewoong Medical, Gimpo, Korea) was developed by Professor Jin Hong Kim in 1999. This stent is a stent-inside-a-stent, where the 
Table 1. History of Trial and Development of Biliary and Enteral Stents in Korea

\begin{tabular}{|c|c|c|}
\hline Year & Stents & Reference no. \\
\hline & Esophageal stent & \\
\hline 1989 & Esophageal plastic endoprothesis & 6 \\
\hline 1992 & Esophageal SEMS & 8 \\
\hline 1999 & Double layered esophageal SEMS for antimigration & 11 \\
\hline 2001 & Antimigration metallic stent & 14 \\
\hline 2001 & Antireflux valve stent & 10 \\
\hline 2004 & SEMS for cervical esophageal cancer & 13 \\
\hline 2005 & Antireflux metallic stent with an antireflux mechanism & 12 \\
\hline 2009 & Drug eluting stent for benign esophageal stricture & 15 \\
\hline \multirow[t]{2}{*}{2014} & TTS fully covered SEMS & 17 \\
\hline & Biliary stent/EUS-guided stent & \\
\hline 1986 & Hand-made large bore plastic stent (10 Fr) & 1 \\
\hline 1992 & Gianturco Rösch biliary Z-stent (Wilson-Cook) & 21 \\
\hline 1998 & Covered biliary metal stent & 22 \\
\hline 2007 & M-Hilar stent (Standard Sci Tech) & 27 \\
\hline 2011 & Y-shaped endoscopic bilateral metal stent placement & 26 \\
\hline 2011 & Large cell D-type biliary metal stent & 28 \\
\hline 2011 & Anchoring flap (M.I. Tech) & 30 \\
\hline 2011 & Bumpy stent (Taewoong Medical) & 29 \\
\hline 2011 & M-intraductal stent (B; Standard Sci Tech) and Kaffes stent (T; Taewoong Medical) & 28 \\
\hline 2011 & EUS-guided stenting; Bona-AL stent (Standard Sci Tech) & 33 \\
\hline \multirow[t]{2}{*}{2011} & Nagi stent for pancreatic pseudoupt drainage (Taewoong Medical) & 34 \\
\hline & Enteral stents & \\
\hline 1988 & Rectal stenting with esophageal Sumitomo-Bakelite stent (Sumitomo-Bakelite) in rectal cancer & 41 \\
\hline 1995 & Gastro duodenal stenting with EsophaCoil (InStent) self-expanding coil stent & 38 \\
\hline 1998 & TTS gastroduodenal stent (Taewoong Medical) & 40 \\
\hline 2004 & TTS colonic stenting & 41 \\
\hline
\end{tabular}

SEMS, self-expandable metal stent; TTS, through-the-scope; EUS, endoscopic ultrasonography.

inner SEMS is covered with a polyurethane membrane to prevent tumor ingrowth and the outer an uncovered SEMS to prevent migration. The mechanism of anti-migration in this double-layered esophageal stent is due to the wire mesh of the outer uncovered SEMS becoming embedded into the esophageal wall. ${ }^{11}$ Professor Shim personally contributed to the development of some new types of covered esophageal SEMS in 2001 (Table 1). Of these, the most representative was the Shim-Hanaro stent and the Shim-Hanaro anti-reflux stent (M.I. Tech), which have recently been approved for use in the United States (Fig. 3A). ${ }^{12}$ A cervical esophageal stent, which was designed with a short proximal flange for use in malignant cervical esophageal stenosis within $2 \mathrm{~cm}$ from the upper esophageal sphincter ${ }^{13}$ (Fig. 3B) and Shim's technique for fixation of partially covered esophageal stent with a string looped around the external ear for the prevention of stent migration, were also notable contributions (Fig. 3C). ${ }^{14}$

This new design was able to overcome many of the problems. However, normal tissue reaction in response to the stent was still an issue, and this led to the development of a paclitaxel drug eluting stent. The response of this new stent was promising in animal studies. ${ }^{15}$

Proximal-releasing stent insertion using a new delivery system (Teawoong Medical), which specializes in the release of the esophageal stent from its proximal end with direct-vision technique and use of transnasal endoscopy without fluoroscopy, was developed in 2006. The anchoring method, where the stent is connected with a silk thread, then looped around the patient's earlobe to prevent migration, is mainly used for the management of the patients, who had postoper- 

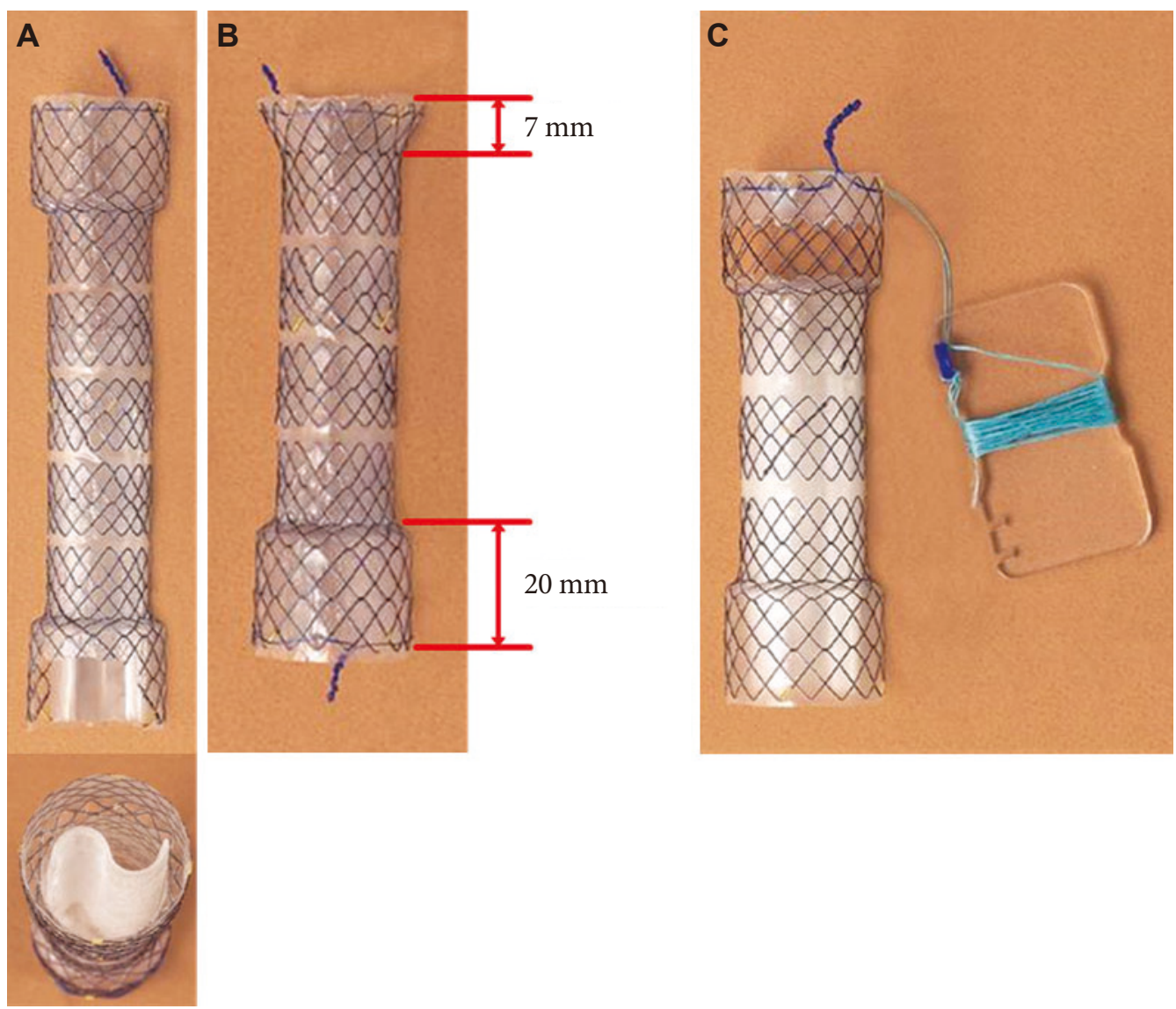

Fig. 3. Special esophageal stents for unusual situations. (A) Self-expandable metal stent (SEMS) with antireflux mechanism with long S-shaped flap. (B) SEMS for upper cervical esophageal cancer, a $7 \mathrm{~mm}$ short upper end of stent in a flask shape to prevent migration. (C) SEMS with Shim's technique for antimigration.

ative esophageal leakage problems. ${ }^{16}$ Professor Shim recently designed a new fully covered, esophageal through-the-scope (TTS) stent, which can pass through the working channel of the endoscope for an easy insertion under direct endoscopic guidance. $^{17}$

\section{BILIARY STENTING}

In the early 1980's, professor Keiichi Kawai (Kyoto Prefectural University of Medicine, Kyoto, Japan), who was Dr. M. Nakajima's mentor, commissioned Olympus for a new large channel duodenoscope, that would be capable of passing a large $10 \mathrm{Fr}(3.7 \mathrm{~mm})$ plastic stent into the biliary tract. Professor Shim had trained in endoscopy under Dr. Nakajima’s supervision in 1982 and was performing clinical trials on patients using plastic polyurethane stents, which Professor Kawai had introduced from Europe. The stent was in its last stages of production. Professor Shim was intrigued with these new and novel ideas and continued to stay in close contact with Dr. Nakajima long after his training period was over. Professor Shim hoped to bring this new technique to Korea
(Table 1, Fig. 1) and eventually asked Dr. Nakajima for a priority supply of the large working channel diameter duodenoscope (TJF; Olympus, working channel, $4.2 \mathrm{~mm}$ in diameter), once it was released into the Japanese market. Dr. Nakajima sent Professor Shim the prototype, large channel, side-viewing duodenoscope, just before it was released in Japan.

In 1979, Soehendra and Reynders-Frederix ${ }^{18}$ first introduced endoscopic biliary drainage using a plastic stent. These early stents were hand-made and specifically cut for the individual patient. Today, plastic biliary stents are standardized and most stents are slightly curved to fit the contours of the common bile duct, so as to prevent stent migration. Plastic stents are made of polyethylene, teflon, or polyurethane. Sideholes are present at both ends of many stent models in order to maintain drainage, if the tip of the stent becomes impacted in the biliary or intestinal wall. Since, it has been suggested that these side holes favor sludge formation, models without side holes, but with multiple side flaps intended to prevent stent migration have been developed. These are known as "Tannenbaum" stents, the name being derived from the German word for fir tree. ${ }^{19}$ The clogging tendency of plastic stents represents a major disadvantage, causing the patient to experience recurrent 
jaundice and cholangitis. The risk of occlusion of standard polyethylene stents appears to increase progressively after 3 months, with an estimated median patency of 4 to 5 months for the $10 \mathrm{Fr}$ plastic stents. Attempts to prolong stent patency, by the addition of an anti-reflux valve or by the use of different coatings on the stent surface, are being tested. ${ }^{20}$

Compared to plastic biliary stents, biliary SEMSs have the advantage of expanding to a much larger diameter than the working channel of the endoscope used for insertion, thus enabling longer patency. However, SEMSs are more expensive and are generally more difficult to remove after deployment. Biliary SEMSs are available in various lengths ranging from 4 to $10 \mathrm{~cm}$, with a stent diameter of $10 \mathrm{~mm}$. They are provided in a constraining sheath, mounted on a delivery catheter and the SEMS expands and usually reaches its nominal length and diameter within a few hours or days after the removal of the constraining sheath. The diameter of the complete assembly ranges from 5.0 Fr (some Leufen stents) to $10.5 \mathrm{Fr}$ (some Shim-Hanaro stents). Biliary SEMSs are also available with covered membranes made of various materials such as polyurethane, silicone, and polytetrafluoroethylene. The biliary

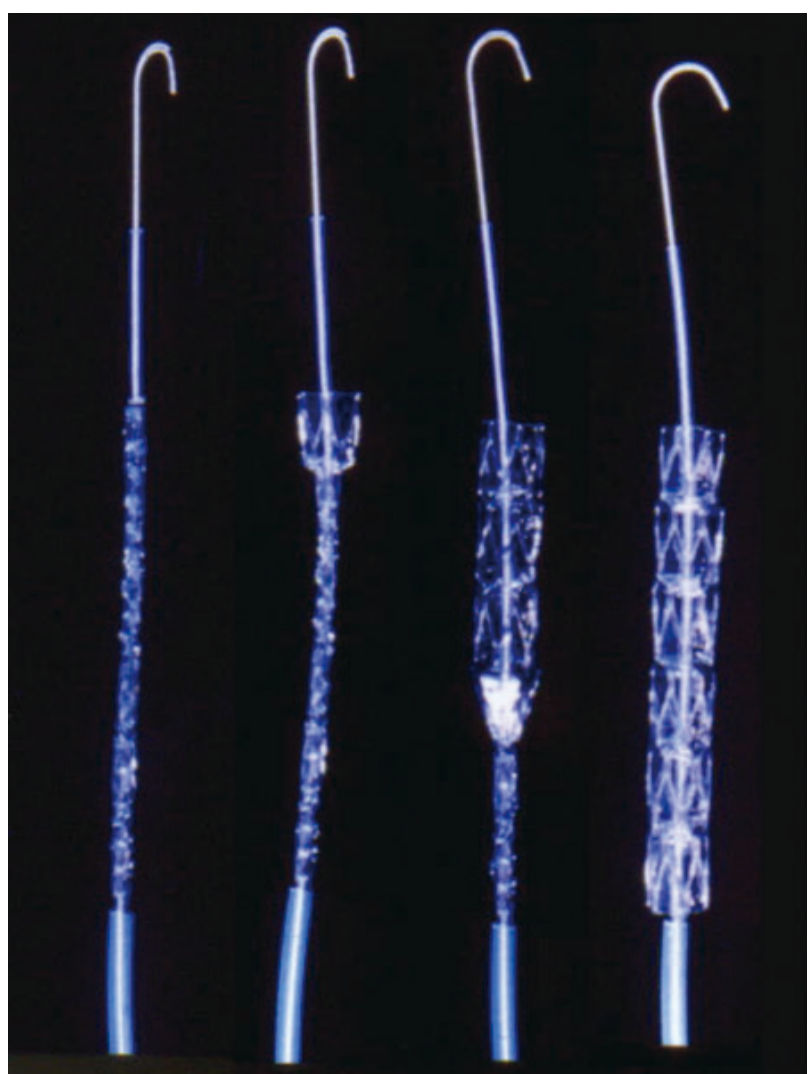

Fig. 4. Hand-made membrane covered biliary self-expandable metal stent. Membrane-covered self-expandable biliary metal stent in expansion after uncoiling the string modified membrane-covered self-expandable biliary metal stent. Stent material, stainless steel $30 \mathrm{Fr}$; membrane, polyurethane; introducing apparatus, string pull type.
SEMSs can be fully or partially covered like the esophageal SEMSs. The delivery catheter is slightly larger for covered SEMs compared to uncovered SEMSs. Professor Shim was the first to report a successful endoscopic application of Gianturco Z-stent in a patient with benign biliary stenosis in $1992^{21}$ and the first to perform an endoscopic application of an uncovered biliary spiral stent (M.I. Tech), which was developed in 1993 (Table 1). Two uncovered biliary SEMSs along with their specialized delivery system for endoscopic placement were developed: the Hanaro biliary stent (M.I. Tech) in 1995 and the Niti-S biliary stent (Taewoong Medical) in 1998.

Covered biliary SEMSs are used to prevent stent occlusion by tumor ingrowth and facilitate stent removal. Professor Shims' first experience with covered biliary SEMS was in 1997, when there were not commercially available. Professor Shim commissioned the application of a polyurethane membrane to a modified Gianturco biliary stent for palliation in patients with malignant biliary obstruction. Polyurethane was not available in Korea and following some research it was obtained from a chemical market in Osaka, Japan (Fig. 4). The preliminary results of this study were promising and led to the development of the Shim-Hanaro Stent (Fig. 5). ${ }^{22}$ Today, it is still controversial, whether covered biliary SEMSs increase stent patency by preventing tumor ingrowth and although data are still limited, several studies have shown an improvement in stent patency with covered SEMSs and most manufacturers produced these models today. ${ }^{23}$ The uncovered D-type biliary stent (Taewoong Medical) and the covered ComVi biliary stent (Taewoong Medical) were developed in the year $2000^{24}$ and $2003,{ }^{25}$ respectively. The uncovered D-type biliary stent improved stent flexibility, while the covered ComVi biliary stent not only improved stent flexibility, but also reduced migration due to its weakened axial force and triple layered structure, which is an e-PTFE (expanded polytetrafluoroethylene) membrane sandwiched between two uncovered nitinol wires.

Bilateral biliary stenting is technically challenging and for overcoming such difficulties in the TTS technique using conventional metal stents, several kinds of newly designed SEMSs have been recently introduced to facilitate passage of the second metal stent during bilateral stenting. The Y-type biliary Niti-S stent (Taewoong Medical), with a wider-mesh portion in the center and smaller-mesh portions at both ends, was developed in 2004. The joining of the Y-stent and the conventional metal stent through the wider-mesh portion of the Y-stent, produces a Y-shaped arrangement. The large opening in the wider-mesh wall of the first Y-stent permits easy passage of the delivery catheter for the second stent and its wide expansion. ${ }^{26}$ There have been other stents, that have been developed for bilateral stenting (M-Hilar stent and K-Hilar 

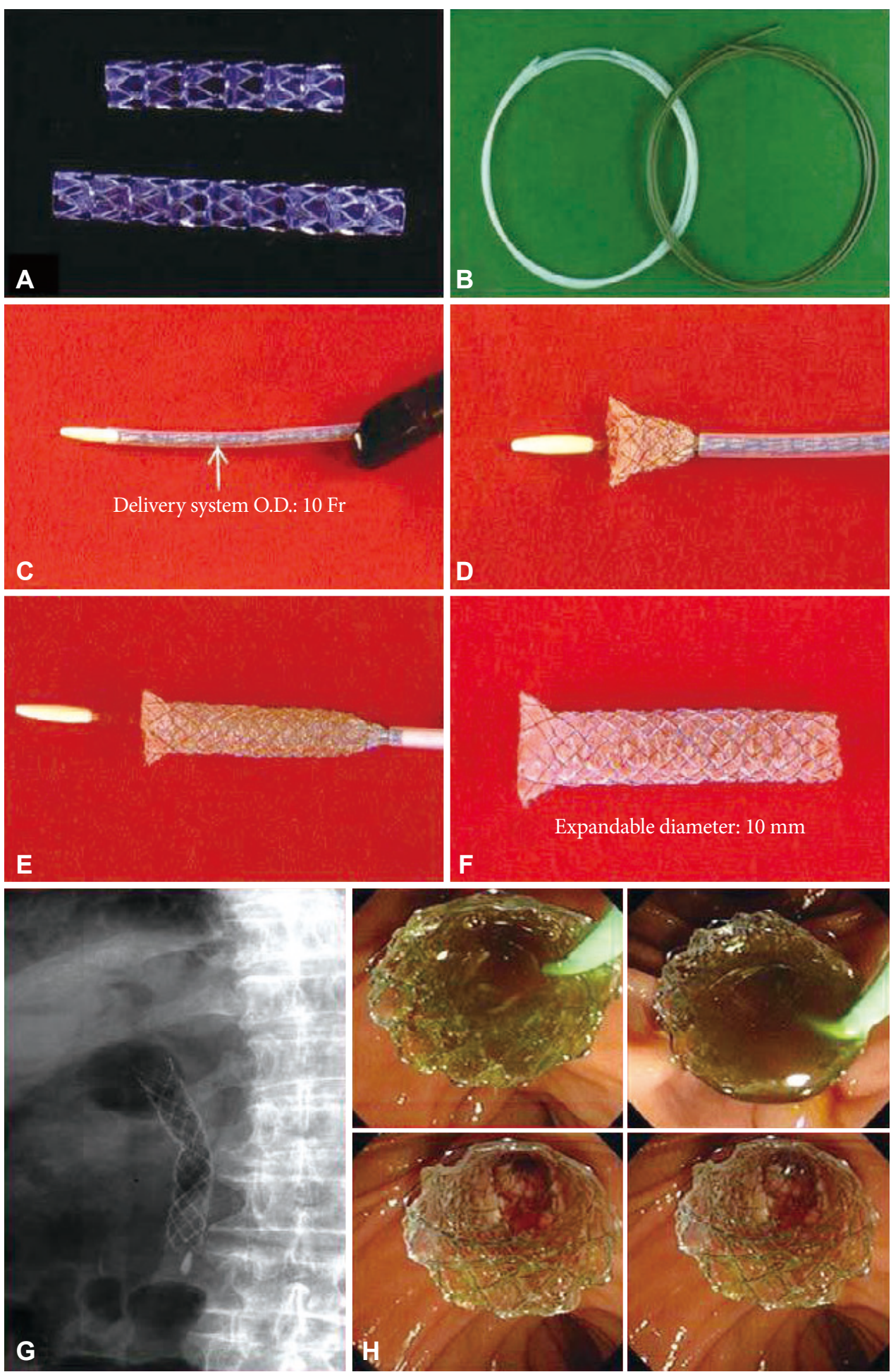

Fig. 5. Covered biliary self-expandable metal stent (SEMS). (A, B) Covered biliary SEMSs and delivery devices. (C-F) Covered biliary SEMSs and expansion from captured position. Implantation of biliary stent into a malignant biliary patient. (G) A X-ray image of fully deployed biliary stent, (H) endoscopic images of fully deployed biliary stent.

stent; Standard Sci Tech, Seoul, Korea). The M-Hilar stent was designed by Professor Jong Ho Moon with a differently woven structure in the center, which permits easy passage of the delivery catheter of the second stent, even though it has no wider-mesh portion. ${ }^{27}$ The K-Hilar stent is another special stent with a large hole in the center of the stent. Lumens of both stents are absolutely patent without blockage of the wire mesh, when this particular stent is used as the second stent 
during bilateral stenting. Large cell D type biliary metal stent (Niti-S LCD biliary stent; Taewoong Medical) with a larger cell diameter of $6 \mathrm{~mm}$, lower axial force, and optimal radial force, was developed to facilitate passage of a second SEMS through any portion of its wire mesh during the TTS technique. This is a simple and easy re-intervention in patients with malignant hilar obstruction. ${ }^{28}$

Several fully covered SEMSs have been developed for the management of benign biliary and pancreatic stenosis, such as Bumpy stent (Taewoong Medical), ${ }^{29}$ which is a new anti-migration design with uneven cell sizes, that is in a repetitive formation of one large and two small, and a fully covered SEMS with an anchoring flap (M.I. Tech), ${ }^{30}$ which is another design of an anti-migration stent that has flaps at the distal end to prevent migration. The results of a comparison study between this stent and a conventional stent with flare ends revealed no migration in this stent, as compared with a $33 \%$ rate of migration in the conventional stent. ${ }^{31}$ Fully covered intraductal
SEMSs, such as M-intraductal BonaStent (Standard Sci Tech) ${ }^{28}$ and Kaffes stent (Taewoong Medical), ${ }^{32}$ were developed for the purpose of preventing sludge build-up, due to the reflux of the duodenal contents. It is advised that when this stent is used, endoscopic sphincterotomy should not be performed, since it is highly likely for reflux of the duodenal contents into the bile duct to occur. These intraductal SEMSs can be easily removed by pulling on the lasso attached to its distal end, with grasping forceps. ${ }^{30}$

Several fully or partially covered SEMSs were specifically designed for endoscopic ultrasonography (EUS)-guided stenting by Professor Sang Soo Lee; Bona-AL stent (Standard Sci Tech) $)^{33}$ for EUS-guided transgastric/transduodenal gallbladder drainage and Hybrid stent (Standard Sci Tech), where the distal half of the stent is covered and the proximal half uncovered, as well as an anti-migration flap at both ends of the covered portion, for hepaticogastrostomy and choledochoduodenostomy. The Nagi stent (Taewoong Medical) ${ }^{34}$ and
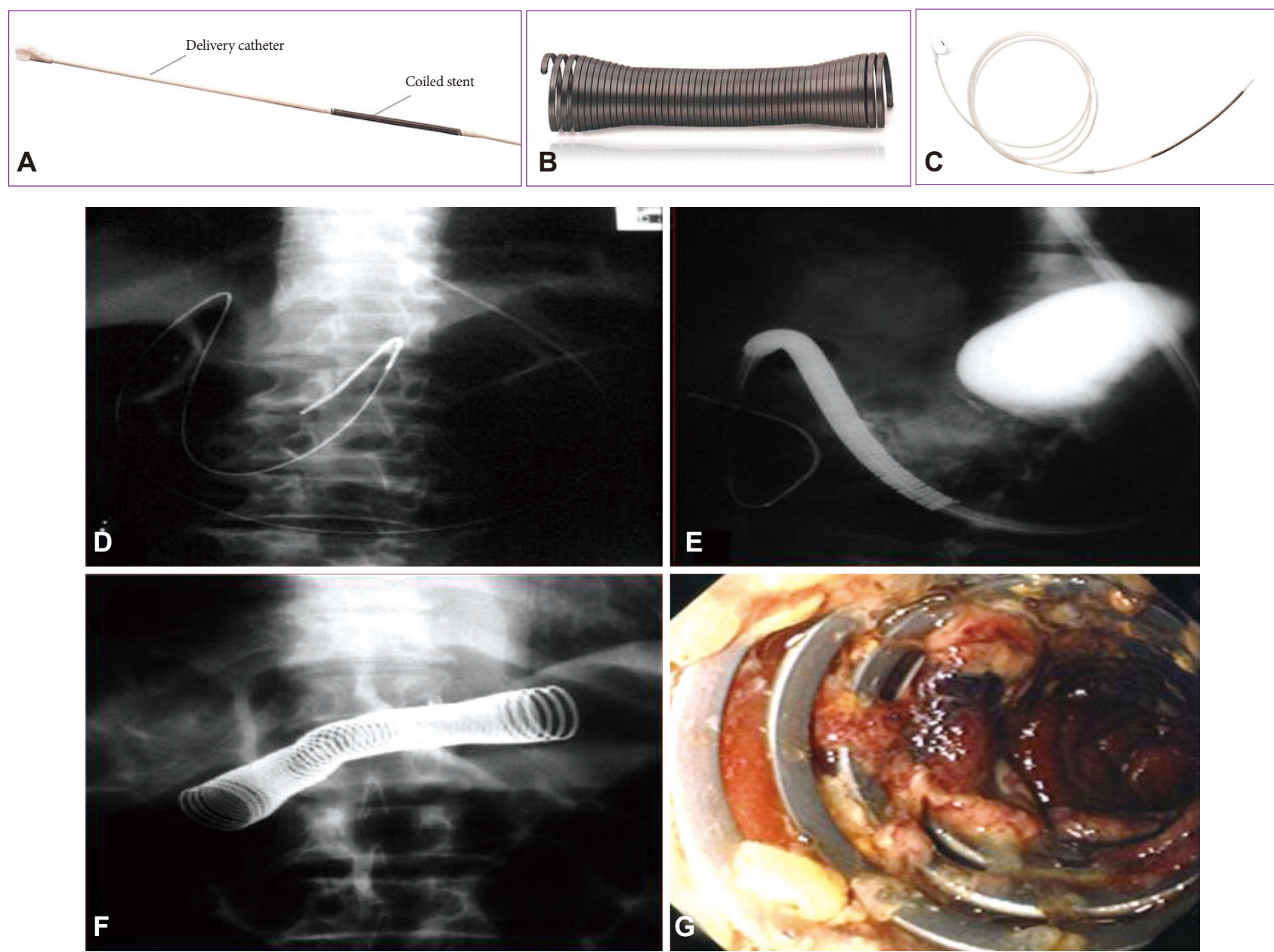

Fig. 6. (A) Original delivery catheter and coiled stent for esophagal stenting. (B) Deployed EsophaCoil (InStent) in vitro. (C) Modified and extended delivery catheter to $150 \mathrm{~cm}$ in length and mounted stent for antroduodenal stenting. Implanting a metallic stent (EsophaCoil stent; InStent) under the fluoroscopic guidance. (D) An image of guide wire inserted deep into duodenum using fluoroscopic image. (E) An image of EsophaCoil stent being inserted following a guide wire. (F) X-ray image after the deployment completed. (G) An endoscopic image of metallic stent placed in gastric outlet region. 
Pseudocyst stent (Standard Sci Tech) are examples of fully covered SEMSs, specifically designed for EUS-guided pancreatic pseudocystic drainage $e^{35}$

Drug eluting metal stents covered with a paclitaxel-incorporated membrane (Niti-S Mira-cover biliary stent; Taewoong Medical) were developed by Professor Dong Ki Lee and have been used in humans since 2003, ${ }^{36}$ resulting in it being technically feasible, safe, and effective in patients with malignant biliary obstruction. However, a prospective, comparative, pilot study between this stent and control covered metal stents, revealed no significant differences in the duration of stent patency and patient survival time. Therefore, further largescaled, prospective, comparative studies were recommended with a new SEMS having the ability to release the chemotherapeutic agent over an extended period of time. ${ }^{37}$

\section{STENTING OF THE STOMACH, DUODENUM, AND COLON}

Gastroduodenal stenting in Korea was first performed in a patient with gastric outlet obstruction due to advanced gastric cancer. However, the original introducing system of an esophageal metal stent (EsophaCoil) was too short to reach the duodenum. Therefore, two introducing systems were connected together to extend the total length, and inserted into the duodenum under fluoroscopy in 1995 (Fig. 6). ${ }^{38}$ However, due to the angulation of the duodenum and the stiff nature of the
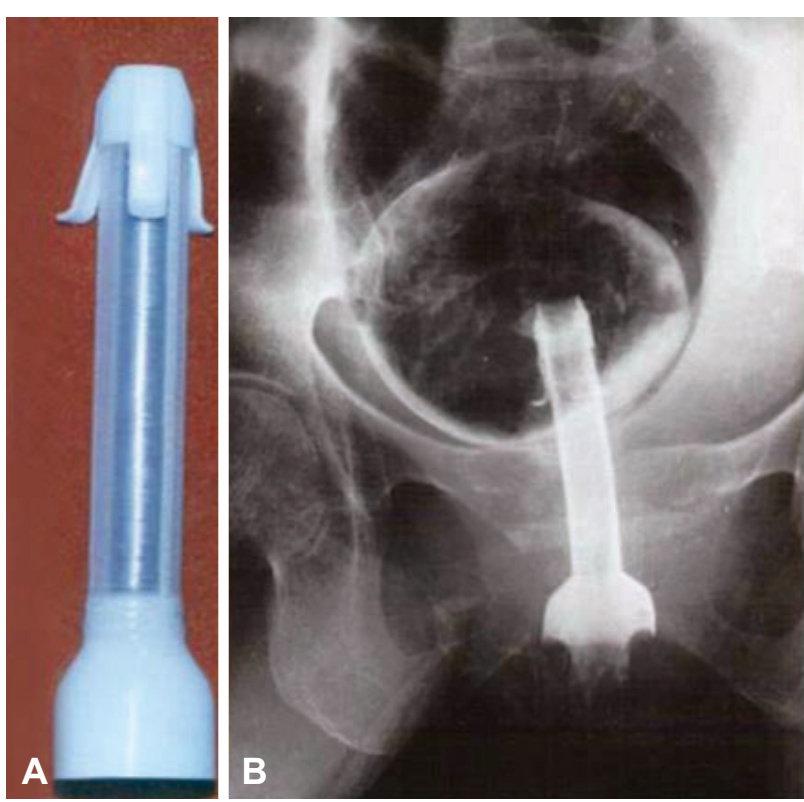

Fig. 7. First trial of rectal plastic stent in 1988. (A) An esophageal plastic stent (Sumitomo-Bakelite Stent; Sumitomo-Bakelite). (B) X-ray image of an esophageal plastic stent in a malignant obstructive rectal cancer patient (an esophageal stent was placed in reverse). stent, it was very difficult to insert, and the procedure was also time-consuming. Following renewed efforts, finally the TTS stent assembly (Niti-S Gastroduodenal stent; Taewoong Medical) using a vascular stent having an $18 \mathrm{~mm}$ diameter along with a novel homemade delivery system was born, and was used successfully in patients with gastric outlet obstruction in 1998. At the same time, the first successful TTS stenting procedure in the United States was being reported by Soetikno et al., ${ }^{39}$ using an enteral Wallstent directly deployed through the endoscope for palliation of malignant gastric outlet obstruction. During the following 2 years, the TTS technique was refined and many physicians began to use the TTS technique in obstructive cancers of the stomach, duodenum, and even strictures of the small bowel. ${ }^{40}$

Occasionally, when rectal or colon cancer completely obstructs the GI tract, the patient is unable to defecate or pass gas and he/she becomes extremely bloated, experiencing dyspnea. Stenting was never an indication for such patients. However, in 1988, Professor Shim decided to attempt colon stenting on patients with total obstructive inoperable rectal cancer using a plastic esophageal stent (Fig. 7). Professor Shim was later quoted as saying "I knew that it was a success as soon as I deployed the stent. The stench and fecal spray confirmed it. The euphoric expression on the patients face was more than enough to help forget the mess on the operating theater and myself.' The TTS technique later evolved to enable stenting of the proximal colon (Table 1, Fig. 8). Up to the early 2000's, colonic stenting was limited to the palliation of the distal colon. More proximal colonic lesions are technically more difficult, as the tortuosity of the colon prevents advancement and positioning of the stent. In 2003, Professor Shim commissioned a partially covered and uncovered Niti-S stent, which was specifically developed for use in the colon (Table 1). The stents consisted of wire-braided nitinol with proximal and distal flanged ends, $15 \mathrm{~mm}$ in length, $24 \mathrm{~mm}$ in diameter, and with a central body having a diameter of $18 \mathrm{~mm}$. The TTS delivery system was 10.5 and $10 \mathrm{Fr}$ for the covered and uncovered model, respectively. Using this new stent, acute proximal colonic obstruction was successfully managed in several patients (Fig. 8$)^{41}$ and it was now possible to stent obstructive cancers anywhere in the colon. Today, stenting is possible at any part of the GI tract, which can be reached by the endoscope.

\section{CONCLUSIONS}

The motivation for developing stents was always to improve the patient's symptoms and quality of life. When facing a suffering patient, physicians must weigh numerous options and constantly question traditional methods. Modern medicine 

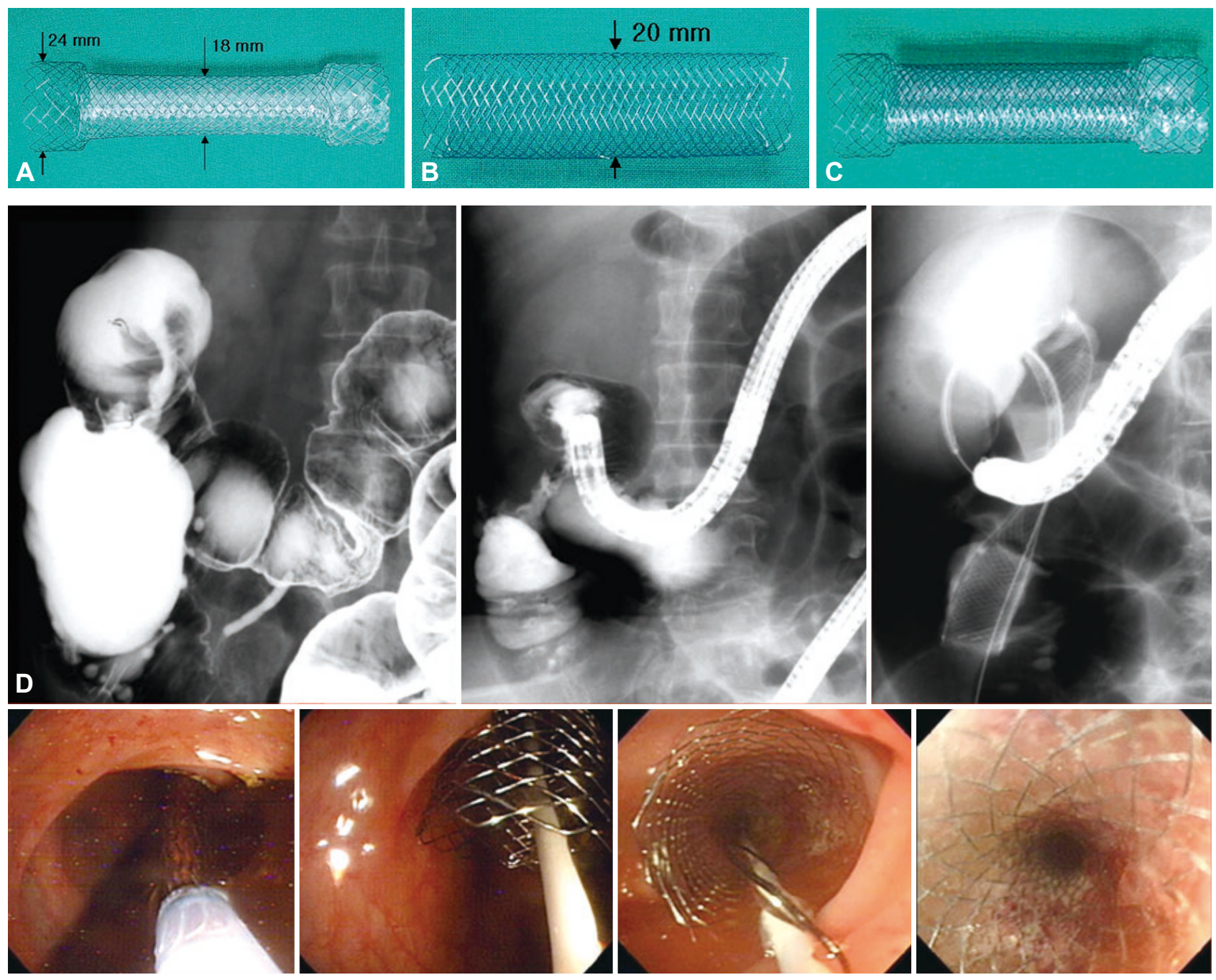

Fig. 8. First trial colonic through-the-scope (TTS) self-expandable metal stent. (A) The partly membrane covered Niti-S stent (Taewoong Medical) with flanges. The proximal part of the flange is not covered with polyurethane. (B) The uncovered Niti-S colon stent, without flanges. (C) The stent-in-stent model (with an outer uncovered stent and an inner partly covered Niti-S stent). (D) Easy stent placement being practiced under an endoscopic view at any obstructed region. Large diameter TTS colonic stent are easily being inserted into a colonoscope channel for easier monitoring of expansion.

has advanced not only with the help of breakthrough technology, but also through questioning individuals, who through their numerous failures, have held on to the hope that they could ease the pain of patients and their families.

If we had submitted to our environment and had not challenged what was already acknowledged, stenting of GI cancer may not be where it is today. Today, Korea has gained worldwide recognition for its cutting edge medical technology. We are confident that the future remains bright as long as physicians continue to be curious and we hope that this process of developing new stents for patients struggling with cancer will continue.

\section{Conflicts of Interest}

The authors have no financial conflicts of interest.

\section{REFERENCES}

1. Shim CS, Yoon SJ, Paik SH, et al. Case series of endoscopic retrograde biliary drainage (ERBD) in malignant obstructive jaundice. Korean J Gastrointest Endosc 1986;6(Suppl):88-89.

2. Celestin LR. Permanent intubation in inoperable cancer of the oesophagus and cardia: a new tube. Ann R Coll Surg Engl 1959;25:165-170.

3. Duseja A, Chawla YK, Singh RP, Sharma TR, Kaur U, Dilawari JB. Dilatation of benign oesophageal strictures: 10 years' experience with Celestin dilators. J Gastroenterol Hepatol 2000;15:26-29.

4. Tytgat GN, den Hartog Jager FC. Non-surgical treatment of cardio-esophageal obstruction: role of endoscopy. Endoscopy 1977;9:211215.

5. Hussain SA, Hughes R, Gross E. Dangers from dissolution of latex in Celestin endo-oesophageal tube. Br Med J (Clin Res Ed) 1987;294:412413.

6. Shim CS, Cho SW, Kim JH, Cho SW. Experience with endoscopic esophageal endoprosthesis in malignant esophagogastric strictures. Korean J Med 1989;36:507-516. 
7. Olsen E, Thyregaard R, Kill J. Esophacoil expanding stent in the management of patients with nonresectable malignant esophageal or cardiac neoplasm: a prospective study. Endoscopy 1999;31:417-420.

8. Song HY, Choi KC, Cho BH, Ahn DS, Kim KS. Esophagogastric neoplasms: palliation with a modified gianturco stent. Radiology 1991;180:349-354.

9. Park HS, Do YS, Suh SW, et al. Upper gastrointestinal tract malignant obstruction: initial results of palliation with a flexible covered stent. Radiology 1999;210:865-870.

10. Do YS, Choo SW, Suh SW, et al. Malignant esophagogastric junction obstruction: palliative treatment with an antireflux valve stent. J Vasc Interv Radiol 2001;12:647-651.

11. Kim MD, Park SB, Kang DH, et al. Double layered self-expanding metal stents for malignant esophageal obstruction, especially across the gastroesophageal junction. World J Gastroenterol 2012;18:3732-3737.

12. Shim CS, Jung IS, Cheon YK, et al. Management of malignant stricture of the esophagogastric junction with a newly designed self-expanding metal stent with an antireflux mechanism. Endoscopy 2005;37:335-339.

13. Shim CS, Jung IS, Bhandari S, et al. Management of malignant strictures of the cervical esophagus with a newly-designed self-expanding metal stent. Endoscopy 2004;36:554-557.

14. Shim CS, Cho YD, Moon JH, et al. Fixation of a modified covered esophageal stent: its clinical usefulness for preventing stent migration. Endoscopy 2001;33:843-848.

15. Jeon SR, Eun SH, Shim CS, et al. Effect of drug-eluting metal stents in benign esophageal stricture: an in vivo animal study. Endoscopy 2009;41:449-456.

16. Lee KM, Shin SJ, Hwang JC, et al. Proximal-releasing stent insertion under transnasal endoscopic guidance in patients with postoperative esophageal leakage. Gastrointest Endosc 2010;72:180-185.

17. Cheon YK, Lee TY, Sung IK, Shim CS. Clinical feasibility of a new through-the-scope fully covered esophageal self-expandable metallic stent: an in vivo animal study. Dig Endosc 2014;26:32-36.

18. Soehendra N, Reynders-Frederix V. Palliative biliary duct drainage. A new method for endoscopic introduction of a new drain. Dtsch Med Wochenschr 1979;104:206-207.

19. Seitz U, Vadeyar H, Soehendra N. Prolonged patency with a new-design Teflon biliary prosthesis. Endoscopy 1994;26:478-482.

20. Chun HJ, Kim ES, Hyun JJ, Kwon YD, Keum B, Kim CD. Gastrointestinal and biliary stents. J Gastroenterol Hepatol 2010;25:234-243.

21. Shim CS, Lee MS, Kim JH, Cho SW. Endoscopic application of Gianturco-Rösch biliary Z-stent. Endoscopy 1992;24:436-439.

22. Shim CS, Lee YH, Cho YD, et al. Preliminary results of a new covered biliary metal stent for malignant biliary obstruction. Endoscopy 1998;30:345-350.

23. Isayama $\mathrm{H}$, Komatsu $\mathrm{Y}$, Tsujino $\mathrm{T}$, et al. A prospective randomised study of "covered" versus "uncovered" diamond stents for the management of distal malignant biliary obstruction. Gut 2004;53:729-734.

24. Yang KY, Ryu JK, Seo JK, et al. A comparison of the Niti-D biliary uncovered stent and the uncovered Wallstent in malignant biliary obstruction. Gastrointest Endosc 2009;70:45-51.

25. Isayama $\mathrm{H}$, Kawabe T, Nakai $\mathrm{Y}$, et al. Management of distal malignant biliary obstruction with the ComVi stent, a new covered metallic stent. Surg Endosc 2010;24:131-137.

26. Hwang JC, Kim JH, Lim SG, Kim SS, Yoo BM, Cho SW. Y-shaped endoscopic bilateral metal stent placement for malignant hilar bili- ary obstruction: prospective long-term study. Scand J Gastroenterol 2011;46:326-332.

27. Lee TH, Park do H, Lee SS, et al. Technical feasibility and revision efficacy of the sequential deployment of endoscopic bilateral side-by-side metal stents for malignant hilar biliary strictures: a multicenter prospective study. Dig Dis Sci 2013;58:547-555.

28. Moon JH, Choi HJ, Koo HC, et al. Feasibility of placing a modified fully covered self-expandable metal stent above the papilla to minimize stent-induced bile duct injury in patients with refractory benign biliary strictures (with videos). Gastrointest Endosc 2012;75:1080-1085.

29. Park do H, Kim MH, Moon SH, Lee SS, Seo DW, Lee SK. Feasibility and safety of placement of a newly designed, fully covered self-expandable metal stent for refractory benign pancreatic ductal strictures: a pilot study (with video). Gastrointest Endosc 2008;68:1182-1189.

30. Park do H, Lee SS, Lee TH, et al. Anchoring flap versus flared end, fully covered self-expandable metal stents to prevent migration in patients with benign biliary strictures: a multicenter, prospective, comparative pilot study (with videos). Gastrointest Endosc 2011;73:64-70.

31. Kogure H, Isayama H, Nakai Y, et al. Newly designed large cell Niti-S stent for malignant hilar biliary obstruction: a pilot study. Surg Endosc 2011;25:463-467.

32. Tee HP, James MW, Kaffes AJ. Placement of removable metal biliary stent in post-orthotopic liver transplantation anastomotic stricture. World J Gastroenterol 2010;16:3597-3600.

33. Jang JW, Lee SS, Park do H, Seo DW, Lee SK, Kim MH. Feasibility and safety of EUS-guided transgastric/transduodenal gallbladder drainage with single-step placement of a modified covered self-expandable metal stent in patients unsuitable for cholecystectomy. Gastrointest Endosc 2011;74:176-181.

34. Itoi T, Nageshwar Reddy D, Yasuda I. New fully-covered self-expandable metal stent for endoscopic ultrasonography-guided intervention in infectious walled-off pancreatic necrosis (with video). J Hepatobiliary Pancreat Sci 2013;20:403-406.

35. Lee BU, Song TJ, Lee SS, et al. Newly designed, fully covered metal stents for endoscopic ultrasound (EUS)-guided transmural drainage of peripancreatic fluid collections: a prospective randomized study. Endoscopy 2014;46:1078-1084.

36. Suk KT, Kim JW, Kim HS, et al. Human application of a metallic stent covered with a paclitaxel-incorporated membrane for malignant biliary obstruction: multicenter pilot study. Gastrointest Endosc 2007;66:798803.

37. Song TJ, Lee SS, Yun SC, et al. Paclitaxel-eluting covered metal stents versus covered metal stents for distal malignant biliary obstruction: a prospective comparative pilot study. Gastrointest Endosc 2011;73:727733.

38. Kim JH, Yoo BM, Lee KJ, et al. Self-expanding coil stent with a long delivery system for palliation of unresectable malignant gastric outlet obstruction: a prospective study. Endoscopy 2001;33:838-842.

39. Soetikno RM, Lichtenstein DR, Vandervoort J, et al. Palliation of malignant gastric outlet obstruction using an endoscopically placed Wallstent. Gastrointest Endosc 1998;47:267-270.

40. Kim JH. Pyloric stenting for malignant gastroduodenal obstruction: the Korean experience. Dig Endosc 2006;18:108-113.

41. Shim CS, Cho JY, Jung IS, et al. Through-the-scope double colonic stenting in the management of inoperable proximal malignant colonic obstruction: a pilot study. Endoscopy 2004;36:426-431. 